\title{
Análise das contribuições potenciais da Avaliação Ambiental Estratégica ao Plano Energético Brasileiro
}

\author{
Analysis of the potential contributions of the Strategic Environmental \\ Assessment to the Brazilian Energy Plan
}

\author{
Simone Mendonça dos Santos \\ Bióloga pela Universidade Federal de São Carlos (UFSCar). Mestre em Ciências da Engenharia Ambiental pela Escola de Engenharia de São Carlos (CRHEA- \\ SHS-EESC/USP)
}

Marcelo Pereira de Souza

Professor Titular da Universidade de São Paulo (USP)

\section{Resumo}

Diante das potencialidades da Avaliação Ambiental Estratégica (AAE) e da importância estratégica do setor energético como objeto de estudo, o presente artigo se utiliza de revisão bibliográfica em literatura específica para identificar as potenciais contribuições da AAE para o Plano Energético Brasileiro. A AAE é discutida como alternativa pertinente para a inserção da variável ambiental nas tomadas de decisão inerentes ao Plano. O instrumento contribui para o estabelecimento de uma agenda ambiental mínima a ser respeitada, essencial à sustentabilidade das atividades de planejamento do setor energético brasileiro. Entretanto, para que atinja plenamente seus objetivos e forneça subsídios à sustentabilidade ambiental, depende do cumprimento de alguns requisitos.

Palavras-chave: Avaliação Ambiental Estratégica; Plano Energético Brasileiro; Plano Nacional de Energia 2030.

\begin{abstract}
Given the potential of the Strategic Environmental Assessment (SEA) and the strategic importance of the energy sector as an object of study, this article uses literature review of relevant literature to identify the potential contributions of the SEA for the Brazilian Energy Plan. SEA is discussed as an alternative to the inclusion of relevant environmental variable in decision-making inherent in the Plan. The instrument contributes to the establishment of a minimum environmental agenda to be respected, essential to the sustain ability of the planning activities of the Brazilian energy sector. However, to fully achieve its objectives and provide subsidies for environmental sustain ability depends on the fulfillment of certain requirements.
\end{abstract}

Keywords: Strategic Environmental Assessment; Brazilian Energy Plan; National Energy Plan 2030

\section{Introdução}

As características tecnológicas e os impactos sociais, econômicos e ambientais da produção, transformação e uso final da energia ressaltam a importância estratégica do setor energético como objeto de estudo. O setor tem grande importância para as economias nacionais e global (THERIVEL et al., 1992), sendo importante em si mesmo como um elemento da produção nacional, um contribuinte essencial para outros setores das economias nacionais (tais como o de transportes e o industrial) e como um componente das atividades domésticas (ORGANIZATION FOR ECONOMIC CO-OPERATION AND DEVELOPMENT- OECD, 1992).

Além da tradicional preocupação dos governos sobre segurança energética e crescimento econômico, atenção tem sido dada aos impactos ambientais do setor, especialmente após estudos do Painel Intergovernamental sobre Mudanças Climáticas (IPCC) que apontaram as atividades energéticas como as principais responsáveis pelo aquecimento global e as emissões atmosféricas (HOUGHTON; JENKINS; EPHRAUMS, 1990).

Ressalta-se ainda que não existe, a priori, determinação sobre os tipos de ações estratégicas que requerem a realização da Avaliação 
Ambiental Estratégica (AAE). A decisão de implementá-la, na maioria dos casos, depende da abrangência da decisão estratégica, do nível de comprometimento do meio ambiente e, mais especificamente, do balanço (trade-off) que se antecipa ocorrer entre as prováveis interferências ambientais adversas e os esperados ganhos econômicos e sociais. No entanto, as decisões estratégicas sobre investimentos em infraestrutura (principalmente nos setores de energia e transporte) e em atividades produtivas (agricultura, mineração e indústria) produzem, reconhecidamente, efeitos ambientais relevantes, sendo, portanto, aquelas para as quais a AAE constitui um instrumento eficiente com o fito de promover o desenvolvimento sustentável (MMA, 2002).

A necessidade de decisões de planejamento de modo mais racional e aberto reforça essa abordagem de resultados ambientais com AAE, a qual pode promover a equidade e a participação pública tanto no tempo como no espaço, conforme destacam Shepherd e Ortolano (1996), ou seja, cedo o suficiente para influenciar decisões maiores que tenham implicações de longo alcance - tempo - e incorporando uma visão participativa de forma mais eficaz que o envolvimento compartimentado em projetos individuais - espaço.

Nesse sentido, o presente artigo, por meio de revisão bibliográfica em literatura específica, identificou e discutiu as potenciais contribuições da AAE para o Plano Nacional de Energia - PNE 2030. Assim, tendo como referência as fases do planejamento descritas por Santos (2006) e o diagrama adaptado de Therivel (2004) sobre a estrutura do processo de AAE, confrontou-se a abordagem da variável ambiental empregada na concepção do referido plano com as potencialidades e o papel da AAE no processo decisório.

\section{0 modelo brasileiro de planejamento da expansão energética}

No Brasil o planejamento integrado dos recursos energéticos foi tradicionalmente negligenciado devido às barreiras institucionais que naturalmente dificultavam a promoção desse objetivo (EPE, 2007). Na prática, até recentemente o Governo Federal só realizava o planejamento da expansão para o setor elétrico, sob a responsabilidade do Ministério de Minas e Energia - MME. Para os outros segmentos do setor energético só se realizavam alguns exercícios de extrapolação das demandas dos recursos energéticos e dos coeficientes técnicos do Balanço Energético Nacional - BEN. Havia a necessidade de se definir estudos de planejamento que quantificassem metas para as políticas energéticas, ou seja, estudos de caráter mais conjuntural (BAJAY, 2001).

Assim, sob a premissa de resgatar e assumir a indelegável função do governo sob as atividades de planejamento como um todo, iniciou-se, no ano de 2004, a reestruturação do planejamento energético brasileiro. Nesse processo, foram priorizados seis produtos para o biênio 2005/2006 (ZIMMERMANN, 2007):

- Plano Decenal de Expansão de Energia Elétrica - PDEE 2006/2015;

- Balanço Energético Nacional - BEN 2030;

- Projeção da Matriz Energética Nacional - MEN 2030;

- Plano Decenal de Expansão de Energia - PDE 2007/2016;

- Plano Nacional de Energia 2030 - PNE 2030;

- Manual de Planejamento - MP.

Nesse contexto, estruturou-se o que se convencionou chamar de Ciclo do Planejamento Energético Integrado. Trata-se de um conjunto de estudos de longo prazo que se autoalimenta, compreendendo quatro etapas principais: a de diagnóstico, a de elaboração de diretrizes e políticas, a de implementação e, por fim, a etapa de monitoração. Estas etapas apóiam-se em duas naturezas de estudos e pesquisas: as análises de diagnóstico estratégico para o setor energético e os planos de desenvolvimento energético.

Entre as análises de diagnóstico estratégico estão os estudos e levantamentos que irão identificar os potenciais energéticos, além da forma e dos custos para seu desenvolvimento. Os estudos do BEN 2030 e da MEN 2030, dentro de uma perspectiva agregada, são exemplos de análises de diagnóstico estratégico, sendo que os primeiros apresentam uma característica estatística e retrospectiva e os segundos possuem uma visão prospectiva.

Os resultados dos estudos e pesquisas de análise e diagnóstico são utilizados diretamente nos planos de desenvolvimento energético, com ênfase na formulação e avaliação de alternativas para atendimento dos serviços energéticos do país, em especial, no elenco de projetos e na elaboração de um plano de ação para a viabilização da expansão da oferta de energia, conforme as diretrizes, princípios e metas definidos, em geral, pela União (Figura 1). Como ponto comum desses estudos, além da clara interdependência entre eles, há o fato de tratarem de informações de caráter nitidamente estratégico, pelo potencial de interferência com o mercado e de mobilização de interesses econômicos (EPE, 2007).

Entre os planos de desenvolvimento energético, encontram-se o PNE 2030 e o PDE 2007/2016. O PNE 2030 possui como objetivo o estabelecimento de estratégias de longo prazo para a expansão do sistema energético nacional tendo em conta as diretrizes da MEN 2030, definindo e analisando os cenários de demanda, os recursos nacionais disponíveis, as possibilidades de importação, as alternativas de gerenciamento da demanda, a evolução tecnológica na oferta e no consumo e, por fim, as condicionantes ambientais. O PDE 2007/2016 indica os projetos para expansão do sistema energético do país, apresentando a alternativa de expansão de menor relação custo/benefício, 


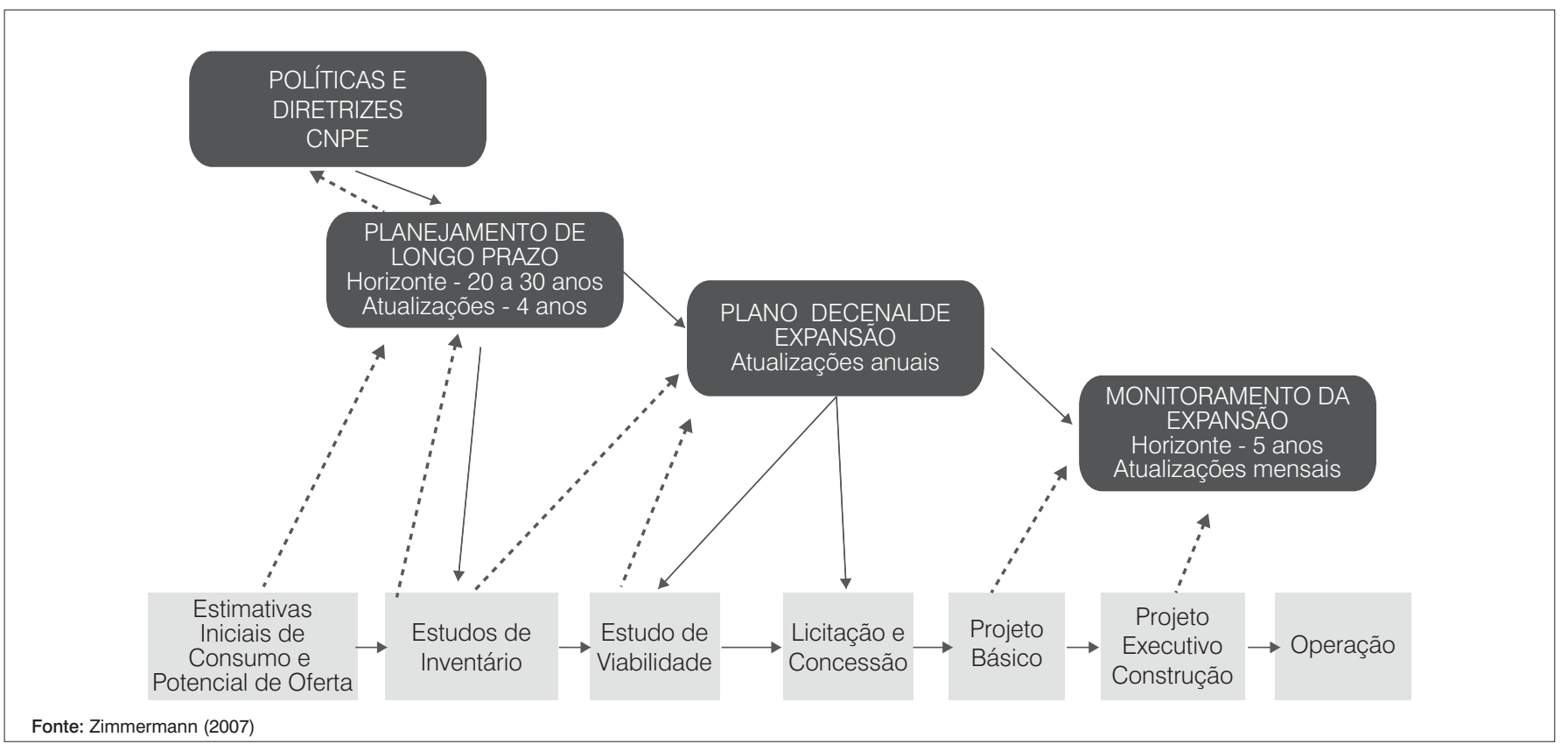

Figura 1 - Planejamento da expansão energética no Brasil.

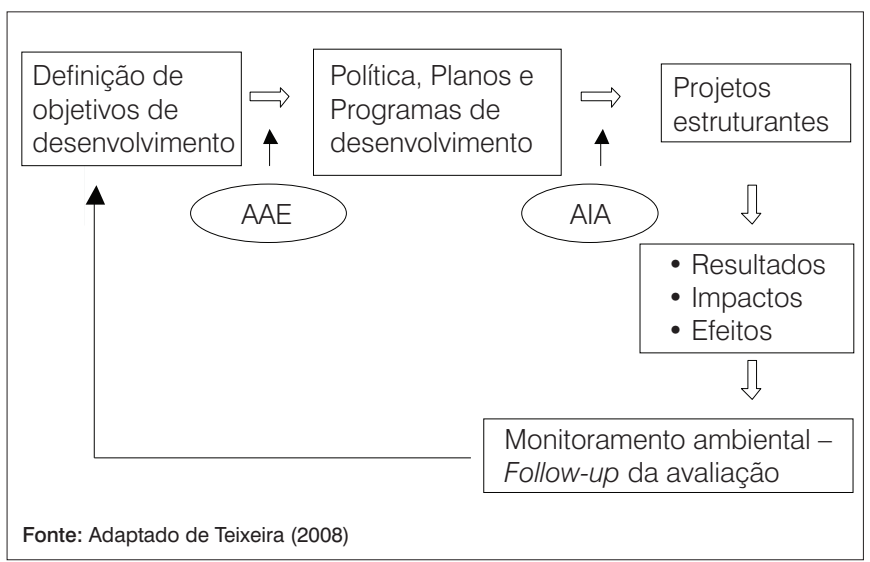

Figura 2 - Ciclo de políticas e a inserção de instrumentos de Avaliação Ambiental.

incluindo os aspectos socioambientais, considerando as estratégias do PNE 2030, as previsões de demanda, as restrições ambientais, a disponibilidade de recursos energéticos, os custos e os prazos e implantação (EPE, 2005).

\section{0 contexto da Avaliação Ambiental}

A relação entre as opções de desenvolvimento, a apropriação (sustentável) da base de recursos naturais e os impactos delas resultantes explicitam o contexto de adoção do processo de Avaliação Ambiental (AA). Trata-se, portanto, de "um processo sistemático de avaliação e documentação de informações sobre as potencialidades, capacidades e funções dos sistemas e recursos naturais, com vistas, em geral, a facilitar o planejamento do desenvolvimento sustentável e a tomada de decisão e, em particular, antecipar e administrar os efeitos adversos e as consequências de iniciativas ou propostas" (SADLER, 1996).

Vários instrumentos e procedimentos de AA têm sido desenvolvidos, na perspectiva de efetivamente atender aos requisitos da prática da gestão do meio ambiente. Nessa perspectiva, entende-se a AA como um processo genérico que inclui a Avaliação de Impacto Ambiental (AIA) de projetos, a Avaliação Ambiental Estratégica (AAE) de Políticas, Planos e Programas (PPP) e um conjunto amplo de metodologias de planejamento e avaliação de impacto (Figura 2) (TEIXEIRA, 2008)

\section{Experiências brasileiras em Avaliação Ambiental Estratégica}

As primeiras iniciativas de AAE no Brasil podem ser identificadas nos anos 1990 e entendidas como pontuais e voltadas para atender demandas específicas. Essas experiências são marcadas por uma abordagem baseada na avaliação de impactos de projetos de grande porte (TEIXEIRA, 2008). Em1994, em virtude da necessidade de obtenção de financiamento por parte do Banco Interamericano de Desenvolvimento (BID) e do Banco Internacional para a Reconstrução e Desenvolvimento (BIRD) o gasoduto Brasil-Bolívia (GASBOL), teve seu projeto inicial 
submetido a processos de avaliação ambiental para definição e otimização da melhor alternativa de traçado para o duto, visando minimizar os impactos ambientais em áreas sensíveis e evitar áreas urbanas e cidades (CRUZ e TOLEDO NETO, 2009).

Uma tentativa de institucionalizar a AAE foi feita em São Paulo no ano de 1994, como consequência de um trabalho de reforma e atualização dos procedimentos de avaliação de impacto ambiental capitaneados pelo Conselho Estadual do Meio Ambiente (CONSEMA). $\mathrm{Na}$ ocasião, a Secretaria do Meio Ambiente chegou a aprovar uma resolução criando uma comissão de avaliação ambiental estratégica no âmbito daquela secretaria, mas os trabalhos não tiveram resultados práticos (SÁNCHEZ, 2008).

O Governo Federal, por intermédio do Ministério do Meio Ambiente (MMA), tem estimulado e capacitado gestores públicos para a utilização do instrumento na tomada de decisão dentro de seus órgãos setoriais, no entanto, a adesão a esses programas de capacitação ainda ocorre voluntariamente (OBERLING, 2008). Em 2002, foi publicado pelo MMA o estudo AAE, como parte do Programa de Fortalecimento Institucional para o Licenciamento Ambiental, incorporando elementos colhidos em seminários realizados em 2001, com a participação de órgãos e instituições governamentais de meio ambiente e planejamento (CRUZ e TOLEDO NETO, 2009). Ainda em âmbito federal, vale mencionar que outro impulso à expansão da AAE decorreu de decisão do Tribunal de Contas da União (Acórdão 464/2004 e outros que se seguiram) que, provocado pelo MMA, executou auditoria de natureza operacional e análise de aplicabilidade da AAE pelo Governo Federal. O acórdão recomenda a adoção da AAE na elaboração do Plano Plurianual e no planejamento de políticas, planos e programas setoriais (SÁNCHEZ, 2008).

No âmbito dos governos estaduais, cabe ressaltar o esforço do estado de Minas Gerais que, com a criação dos núcleos de gestão ambiental, grupos dentro das secretarias estaduais disseminadores da transversalidade da política ambiental, a operacionalização dos programas estratégicos de cada secretaria está sendo submetida a estudos de AAE. Já ocorreram estudos para o Plano de Transporte de Minas Gerais e o Plano de Geração de Energia Elétrica, ambos concluídos em 2007

No setor privado, as duas iniciativas foram a realização de AAE na exploração e produção de petróleo e gás natural na Bacia de Camamu-Almada (BA), ocorrida em 2005, e da AAE do Programa de Desenvolvimento do Setor Produtivo de Corumbá e Influências sobre a Planície Pantaneira, em 2007/2008. Em ambos, buscou-se analisar as opções de desenvolvimento de indústrias de alto potencial poluidor, petróleo no primeiro e mineração/siderurgia, no segundo, frente aos seus possíveis impactos em dois frágeis ecossistemas -o litoral sul da Bahia e o Pantanal (MARIANO, 2007).
Em linhas gerais, a experiência brasileira em AAE pode ser dividida em dois momentos distintos. O primeiro envolve iniciativas pontuais, voluntárias ou sugeridas como parte dos requisitos para a concessão de financiamento externo, na esfera dos projetos de infraestrutura, e desvinculadas de qualquer estruturação de um sistema de AAE. O segundo está associado à tentativa de o Governo Federal, por meio dos Ministérios do Meio Ambiente e do Planejamento, definir os elementos necessários à discussão sobre um sistema de AAE no Brasil (TEIXEIRA, 2008).

Dessa forma, nos últimos anos, iniciativas de avaliação ambiental estratégica têm se multiplicado no Brasil; no entanto, cabe ressaltar que, a AAE ainda não foi regulamenta por lei. Atualmente, as iniciativas ocorrem em função da crença individual de gestores, públicos ou privados, no poder e na eficiência do instrumento como facilitador da tomada de decisão. As iniciativas dos estudos são lideradas pelo setor governamental (federal ou estadual), mas também se verificam alguns casos na iniciativa privada e no terceiro setor (OBERLING, 2008).

Por outro lado, um nítido impulsionador da AAE no Brasil tem sido a dificuldade de licenciamento ambiental de certos projetos de grande porte (SANCHÉZ, 2008). Entretanto, além das limitações e indicações que emergem do amadurecimento da prática do licenciamento ambiental, a discussão em torno da oportunidade da adoção da AAE no Brasil também tem sido motivada pela demanda de instituições financeiras internacionais -Banco Mundial e BID -, quando do financiamento de programas de desenvolvimento (TEIXEIRA, 2008).

\section{Resultados e discussão}

\section{Plano Nacional de Energia e a abordagem da variável ambiental}

O PNE 2030 é importante instrumento do planejamento de longo prazo do setor energético brasileiro que, juntamente com a elaboração da MEN 2030, subsidia a elaboração dos estudos de curto e médio prazos, como os dos planos decenais de expansão de energia.

Frente à importância estratégica do PNE 2030 e aos potenciais impactos ambientais das ações nele previstas, analisou-se a abordagem da variável ambiental empregada na concepção do referido plano. Para tanto, com base no exemplo de estruturação geral das fases do planejamento de Santos (2006), foram descritos os principais procedimentos e conteúdo do PNE 2030 (Quadro 1).

A análise dos principais procedimentos e conteúdo do PNE 2030 identifica uma estrutura de planejamento forte em modelos 
Quadro 1 - 0 Plano Nacional de Energia 2030 - Procedimentos e conteúdo

Planejamento - Santos (2004)

\section{Fases}

Definição de objetivos

Obtenção de consenso entre vertentes

Consenso -

Consenso institucional, técnicocientífico e comunitário
Plano Nacional de Energia 2030 - MME: EPE (2007)

Procedimentos/ contéudo

- O planejamento de longo prazo do setor energético do país, orientando tendências e balizando alternativas de desenvolvimento para as próximas décadas, por meio da formulação de uma estratégia de expansão da oferta de energia e do atendimento a diferentes cenários de evolução da demanda, segundo uma perspectiva de longo prazo para o uso integrado e sustentável dos recursos disponíveis.

- Consenso institucional e técnico-científico na definição de um conjunto de notas técnicas que documentaram estudos sobre a evolução da demanda (formulação de cenários de longo prazo para a evolução da economia mundial, bem como a caracterização e quantificação de cenários para a economia nacional àqueles relacionados), sobre quantificação e projeção demográfica, sobre o progresso autônomo da eficiência energética (avanços tecnológicos e hábitos incorporados no uso da energia e, por fim, sobre os recursos energéticos (caracterização técnico-econômica de cada um como fonte de energia e descrição os aspectos socioambientais envolvidos em suas utilizações).

- Conjugação de informações para a elaboração das notas técnicas, definidas em um Termo de Referência (TR) anexo ao contrato dos estudos pelo Ministério de Minas e Energia (MME) à Empresa de Pesquisa Energética (EPE), por meio da realização de encontros temáticos com renomados técnicos e profissionais e consultas a publicações como teses e periódicos, além de web sites de instituições relevantes no tema.

- Estudos desenvolvidos pela EPE, coordenados pela Secretaria de Planejamento e Desenvolvimento Energético (SPE) do MME, com o apoio do Centro de Pesquisa de Energia Elétrica (CEPEL).

- Contrato de estudos e definição de TR pelo MME à EPE que pôde contar com o auxílio de consultores externos, por ela mesma contratados, ou cedidos diretamente pelo MME.

- Âmbito nacional.

Área de influência área institucional/bacia hidrográfica/regional/local

estudo financeiros)-comprometime engajamento de instituições técnicos; mobilização de recursos financeiros

Escala -

Seleção da(s) escala(s) de trabalho seleção de escalas sintéticas ou analíticas

Inventário

Banco de dados definição de categorias, fatores e parâmetros indicadores; coleta de dados; definição dos tipos de parâmetros indicadores (qualitativo, quantitativo, multicategórico, etc.); ordenação e ponderação dos parâmetros indicadores

Análise integrada avaliação de fragilidades e potencialidades, acertos e conflitos; avaliação dos cenários passados e presentes
- Escala sintética: recursos energéticos, competitividade atual entre os recursos energéticos em função das condições regulatórias e dos aspectos econômicos e ambientais, aspectos ambientais da oferta e consumo de energia, sistemas de transmissão de energia elétrica, inovações tecnológicas do setor elétrico.

- Escala analítica: população economia, oferta e consumo de energia, mercado de energia elétrica, sistemas de transmissão de energia elétrica, inovações tecnológicas do setor elétrico.

- Escalas analíticas temporais: 1970-2005 e 2005-2030.

- Escalas geográficas: Regiões geoelétricas, bacias hidrográficas, subsistemas do país (Norte, Nordeste, Sudeste/Centro-Oeste e Sul).

- Histórico demográfico e de domicílios;

- Histórico da economia brasileira;

- Síntese do balaço energético nacional;

- Síntese da evolução do consumo final e conservação de energia elétrica;

- Estudos e inventários dos recursos energéticos no Brasil bem como das estruturas de oferta e processamento, transporte e distribuição incorporando-se caracterização técnica e econômica das tecnologias.

- Síntese da matriz energética nacional de longo prazo - MEN 2030, fornecida pelo MME.

- Análise da evolução histórica da população e da economia brasileira.

- Sumarização de estatísticas, parâmetros e correlações para os indicadores energéticos extraídos do - BEN 2030

- Análise descritiva da evolução da oferta e do consumo de energia no Brasil;

- Apresentação dos principais centros de carga, tendo como referência os barramentos das usinas e a demanda máxima correspondente.

- Descrição do potencial dos recursos hídricos no Brasil com a identificação dos principais conflitos potenciais com relação às Unidades de Conservação, terras indígenas, quilombos e reservas extrativistas e peculiaridades e políticas de desenvolvimento sustentável para a região.

- Avaliação da disponibilidade de cada fonte energética, com análise genérica de alguns aspectos socioambientais e identificação dos principais usos prioritários futuros. - Levantamento preliminar das tecnologias em desenvolvimento conceituawl ou em estágio de protótipo que poderiam ser desenvolvidas no longo prazo. 
Quadro 1 - Continuação

Planejamento - Santos (2004)

Fases

\section{Procedimentos}

Avaliações temporais identificação de alternativas; construção de possíveis cenários futuros

Plano Nacional de Energia 2030 - MME: EPE (2007)

Procedimentos/ contéudo

\section{- Cenários econômicos de evolução da economia brasileira no longo prazo.}

- Cenários de evolução do mercado de energia elétrica no longo prazo considerando os subsistemas do país, compatíveis com as hipóteses demográficas, econômicas e de conservação e uso eficiente da energia.

- Projeção da oferta e consumo dos recursos energéticos.

- Trajetórias futuras de evolução dos sistemas de transmissão do país.

- Projeção das emissões de $\mathrm{CO}_{2}$, por fonte e por setor, no longo prazo.

- Evolução das emissões específicas com base na oferta de energia.

- Alternativas de expansão da geração de energia elétrica, designadamente as alternativas de expansão do mix hidrotérmico ${ }^{1}$ pela utilização do Modelo de Expansão da Geração no Longo Prazo -MELP², que indicou as opções de geração para cada um dos subsistemas considerados e adicionalmente o dimensionamento ótimo das interligações elétricas entre eles.

- Identificação do horizonte temporal de aproveitamento do potencial hidrelétrico economicamente competitivo e ambientalmente viável para a identificação de alternativas de geração termelétrica pelos diversos tipos de fontes, nas diferentes regiões do país no longo prazo.

Tomada de decisão

Seleção de alternativas avaliação técnica, jurídica, administrativa e financeira das alternativas; hierarquização.

Formulação de diretrizes
Instrumentação técnica, jurídica e administrativa -

definição de normas para a organização territorial; elaboração de planos e programas; propostas de monitoramento e controle; proposição de subsídios ao gerenciamento; elaboração de mecanismos de gestão
- A aplicação do MELP selecionou a melhor alternativa, do ponto de vista econômico, para a expansão conjunta da geração e de blocos de transmissão, considerando os cenários de mercados estabelecidos.

- Considerar a fonte primária hidrelétrica como a opção prioritária, em termos quantitativos, para o suprimento dos requisitos de energia elétrica do país, no período de 2015 a 2030.

- Planejar o aproveitamento das bacias hidrográficas da região Norte, por razões de viabilidade socioambiental, sem grandes reservatórios de regularização plurianual. - Reavaliar com novos estudos de engenharia e socioambientais, a parcela de 86 GW do potencial hidrelétrico nacional, não considerada na parcela a ser aproveitada até 2030 por baixa competitividade econômica e socioambiental.

- Priorizar a realização, até 2012, dos estudos de inventário das bacias hidrográficas e dos rios onde se localizam as usinas hidrelétricas consideradas para aproveitamento até 2030.

- Prosseguir o aproveitamento dos recursos hidrelétricos nacionais, incluindo as Pequenas Centrais Hidrelétricas, nos montantes estabelecidos por este Plano, nas diversas regiões geográficas do país.

- Incorporar nos futuros Planos Decenais um programa termelétrico nos montantes identificados neste Plano e analisar sua economicidade visando à inclusão de usinas termelétricas nos futuros leilões de energia, nas regiões geográficas identificadas neste Plano.

- Definir o prosseguimento do Programa Nuclear Brasileiro, após Angra III, com uma expansão mínima de 4 GW, podendo alcançar 8 GW até 2030, nas regiões Sudeste e Nordeste, iniciando os estudos de localização destas novas centrais nucleares. - Programar a elevação da produção de petróleo, do valor atual de 1,7 milhões de barris/dia em 2005, para 3 milhões de barris/dia em 2030, procurando ajustar a produção à demanda prevista, mantendo neste horizonte de longo prazo a autosuficiência nacional no setor de petróleo.

- Considerar a agroenergia como uma contribuição importante para a solução dos problemas da sustentabilidade do fornecimento de combustíveis, com menor impacto ambiental, social e econômico para o consumidor. Monitorar as áreas agriculturadas e agriculturáveis, e investir em tecnologia para a melhoria do processo produtivo, de forma a assegurar o desenvolvimento sustentável.

- Promover a elevação da produção nacional de gás natural, reduzindo a necessidade de importação no longo prazo, minimizando a dependência do país deste energético. Realizar um estudo específico visando estabelecer a participação mais adequada, quanto às importações, sob a ótica de estratégia de abastecimento, entre gasodutos oriundos dos países vizinhos.

- Promover a eficiência energética para que se torne uma opção sustentável aos investimentos na expansão da oferta de energia, com o objetivo de minimizar impactos ambientais, por meio de mecanismos estruturantes e operacionais, para induzir os consumidores e produtores de energia a atingir as metas definidas neste Plano. - Direcionar os recursos de pesquisa e desenvolvimento disponíveis no setor para as áreas prioritárias estudadas neste documento, com especial destaque para os temas bioenergia, eficiência energética e energias renováveis, além de reservar uma parcela dos recursos para novas pesquisas.

'Geração hidrelétrica, a carvão mineral, nuclear, a gás natural, por fontes alternativas e cogeração; ${ }^{2}$ Desenvolvido por Machado Junior et al. (2000) e posteriormente modificado por pelo Centro de Pesquisas de Energia Elétrica (CEPEL), Modelo de Expansão da Geração no Longo Prazo(MELP) é um modelo matemático que incorpora aspectos de incerteza à decisão e fornece estratégias de expansão. Com base nos diversos cenários de demanda, a estratégia para a expansão é determinada em duas etapas: Inicialmente são definidos os planos de expansão ótimos para cada cenário e, em seguida, os custos obtidos com essa etapa são utilizados para se calcular o arrependimento de cada projeção da demanda na estratégia conjunta válida para todas as situações. 
econômicos, porém, fraca em modelos ecológicos, de forma que, sob o discurso da definição de uma estratégia de expansão da oferta de energia, dentro da ótica de desenvolvimento sustentável do país, o PNE 2030, de fato, não insere a variável ambiental no processo decisório. Os estudos de inventário e diagnóstico, por exemplo, apesar de admitirem a existência de alguns conflitos potenciais com relação às unidades de conservação, terras indígenas, quilombos, reservas extrativistas e às políticas de desenvolvimento sustentável para as regiões com potencial hídrico, limitaram-se à realização de descrições genéricas sobre tais assuntos, de forma que, não se pode verificar se essas informações foram ou não ponderadas na tomada de decisão.

Mesmo diante da proposta de planejamento de longo prazo para o uso integrado e sustentável dos recursos disponíveis, não se identifica, no PNE 2030, a realização de estudos e análises acerca das oportunidades e restrições e impostas por outras ações estratégicas direta ou indiretamente relacionadas. A compatibilização entre objetivos de proteção ambiental, por exemplo, é prevista, apenas, para níveis mais baixos da hierarquia de planejamento, centrandose, essencialmente, no processo de licenciamento ambiental de empreendimentos energéticos.

Verifica-se, ainda, que nos estudos realizados no âmbito do PNE 2030, a participação pública ocorreu de maneira tardia ao processo decisório, por meio de consulta aos seminários temáticos sobre os principais tópicos abordados no plano, procedimento que, na prática, apenas justificou ao público as decisões já tomadas. Assim, mesmo que as contribuições recebidas nesses seminários, e ainda aquelas encaminhadas ao MME ou à EPE (as apresentações foram disponibilizadas no site do MME e da EPE, abrindo-se a possibilidade de encaminhamento de questionamentos, contribuições e sugestões), tenham sido incorporadas aos estudos, tais procedimentos, sozinhos, não implicam compromisso, por parte dos tomadores de decisão, com o atendimento às referências ambientais e às considerações da comunidade.

Portanto, no PNE 2030 não se identificam procedimentos de orientação à tomada de decisão sobre a exclusão de alternativas

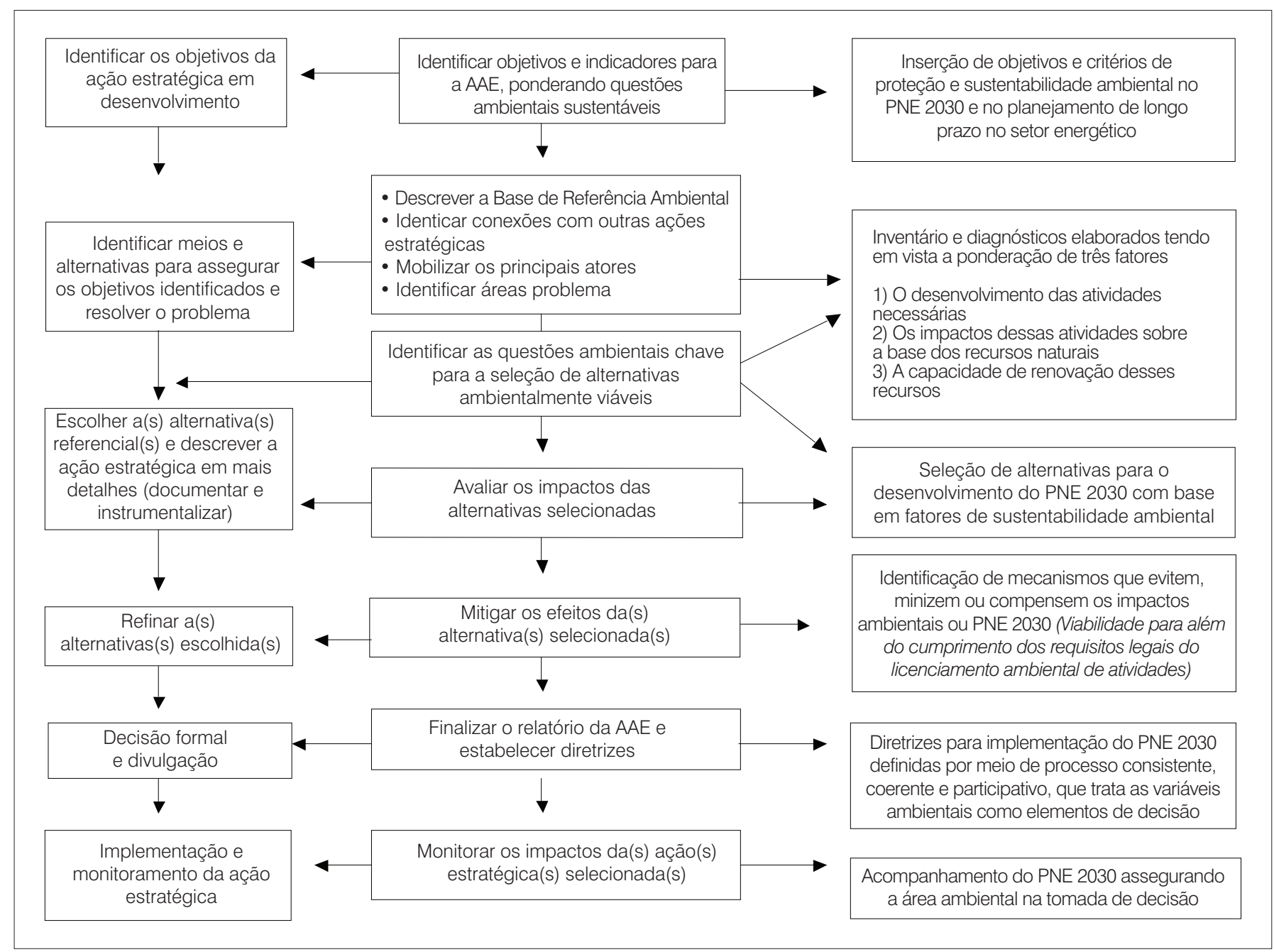

Figura 3 - A Avaliação Ambiental Estratégica (AAE) e o Plano Nacional de Energia 2030 (PNE 2030). 
de expansão da oferta de energia por motivos ambientais. A abordagem da variável ambiental é insuficiente para compatibilizar a viabilidade ambiental das ações previstas no referido plano. Além disso, os procedimentos de articulação entre as vertentes (institucional, técnico-científica e comunitária) empregados não viabilizaram a compatibilização entre objetivos estratégicos e de interesse nacional, de sustentabilidade e proteção ao meio ambiente.

\section{As contribuições da Avaliação Ambiental Estratégica para o Plano Nacional de Energia 2030}

A fim de examinar as potenciais contribuições da AAE para o PNE 2030 e, tendo como referência o diagrama adaptado de Therivel (2004), foi estabelecida correspondência entre as etapas de procedimentos da AAE e os principais e procedimentos e conteúdo do referido Plano (Figura 3).

A Figura 3, além de expor as principais contribuições da AAE para o PNE 2030, destaca as etapas sequenciais básicas previstas para aplicação do instrumento, propondo sua integração na concepção de ações estratégicas. Verifica-se, portanto, que, se aplicada à concepção do PNE 2030, a AAE contribuiria com objetivos de proteção e sustentabilidade ambiental - possibilitando a definição de objetivos de planejamento com base não apenas em fatores econômicos ou de mercado, como se observou pela análise dos procedimentos e conteúdo do PNE2030 - e, simultaneamente, forneceria mecanismos para o alcance de tais objetivos, ponderando os fatores ambientais como elementos de decisão.

O instrumento contribuiria, ainda, para a estruturação de uma base de dados ambientais que subsidiaria a tomada de decisão sustentável o que, no contexto e estrutura do PNE 2030, possibilitaria estudos de inventário e diagnóstico que ponderassem o balanço entre o desenvolvimento das atividades energéticas, os efeitos dessas atividades na base de recursos naturais e na capacidade de renovação desses recursos.

Nesse sentido, modelos participativos são boas alternativas para a obtenção de melhores resultados no que diz respeito ao diagnóstico das áreas problemas ou, em outras palavras, das questões chave, pois ponderam os valores e anseios das partes interessadas e as compatibilidades e restrições impostas por outras ações estratégicas para a tomada de decisão sustentável. Além disso, a antecipação, para níveis mais elevados da escala de planejamento, da compatibilização entre objetivos estratégicos, com destaque para os de proteção e sustentabilidade ambiental, identifica, precocemente, questões polêmicas que poderiam surgir por ocasião do licenciamento ambiental de atividades.

Ademais, observa-se que, ao inserir objetivos de sustentabilidade e proteção ambiental no PNE 2030, a AAE contribuiria para que a análise dos cenários passados e presentes, a formulação e avaliação de alternativas para a expansão energética ponderassem a variável ambiental, possibilitando a seleção de alternativas sustentáveis e a identificação de mecanismos de mitigação e gerenciamento dos impactos ambientais do referido plano. Assim, ponderada a variável ambiental, a inserção de mecanismos de mitigação e gerenciamento de impactos na concepção do PNE 2030 dinamizaria o estudo da viabilidade ambiental das atividades energéticas dele decorrentes, uma vez que anteciparia o estudo da cumulatividade e sinergismo dos impactos ambientais e incorporaria medidas ambientais mais estratégicas, eliminando os custos associados e diminuindo o tempo necessário para a elaboração dos Estudos de Impacto Ambiental (EIA), na ocasião do licenciamento ambiental.

Por fim, tem-se que, com a AAE, metas e métodos de monitoramento da implementação do PNE 2030 no ambiente sejam previamente identificadas de forma a possibilitar o acompanhamento dos efeitos ambientais do plano em relação ao que foi previsto e/ou a identificação de impactos adversos não previstos. Além disso, a adoção de mecanismos de monitoramento informaria o processo de AAE sobre a integração da variável ambiental no processo decisório. Cabe ressaltar a inexistência de tais mecanismos no conteúdo do PNE 2030.

\section{Conclusões}

Nos últimos anos, iniciativas de AAE têm se multiplicado no Brasil. No entanto, pode-se afirmar que a prática brasileira carece de diretrizes em torno de um denominador comum no que diz respeito aos objetivos, alcance e potencialidades do instrumento. Diretrizes que possam subsidiar os processos de planejamento com princípios, padrões e/ou critérios de desempenho para a AAE, o que a consolidaria como um importante instrumento de planejamento no país.

Além disso, pela análise dos procedimentos e conteúdo do PNE 2030, verificou-se que, apesar do reconhecimento, por parte dos tomadores de decisão, da necessidade de reestruturação do processo de planejamento do setor energético brasileiro, a abordagem da variável ambiental empregada na concepção do PNE 2030 é insuficiente para compatibilizar adequadamente o desenvolvimento das atividades setor e a proteção ambiental. Ela trata a variável ambiental apenas como um fator de restrição ou impedimento para a expansão da oferta de energia - são indicados os condicionantes socioambientais para cada fonte/empreendimento energético. Nesse contexto, não se identificam procedimentos de orientação à tomada de decisão sobre a exclusão de alternativas de expansão da oferta de energia por motivos ambientais.

Por outro lado, as informações analisadas e os resultados obtidos evidenciam o potencial da AAE como alternativa para a integração antecipada da variável ambiental nas tomadas de decisão inerentes ao PNE 2030. O instrumento, diante da necessidade de 
modelos de planejamento que conciliem alternativas de desenvolvimento e proteção ambiental, contribui para o estabelecimento de uma agenda ambiental mínima a ser respeitada, essencial à sustentabilidade das atividades do setor energético. Entretanto, para que atinja plenamente seus objetivos e forneça subsídios à tomada de decisão e à sustentabilidade ambiental, no âmbito das atividades previstas pelo PNE 2030, o instrumento conta com o cumprimento de alguns requisitos:

- Cooperação institucional para o desenvolvimento integrado das atividades previstas pelo PNE 2030 com aquelas designadas por outras políticas, planos ou programas direta ou indiretamente relacionados, por meio da prévia identificação das eventuais sinergias e/ou constrangimentos entre os objetivos estratégicos;

- Adoção antecipada de abordagens que equacionem o equilíbrio entre as variáveis ambiental, social e econômica para a tomada de decisão;

- Comprometimento por parte dos tomadores de decisão com o desenvolvimento de alternativas sustentáveis de expansão da oferta de energia, por processos participativos e ambientalmente responsáveis de diagnóstico das potencialidades e susceptibilidades do meio ambiente;

- Estímulo à produção contínua de informações sobre referências e critérios de sustentabilidade por meio de um sistema transparente de informação, que articule produção, sistematização e monitoramento de informações ambientais, econômicas e sociais.

Portanto, entende-se que a aplicação da AAE no contexto brasileiro de planejamento da expansão energética é caminho a ser percorrido no desenvolvimento com sustentabilidade. Dessa forma, o presente artigo reforça a necessidade regulamentação e institucionalização da AAE no país, pois, ao inserir a variável ambiental na tomada de decisão,o instrumento agrega valor a uma agenda de políticas públicas tradicionalmente desvinculada dos aspectos ambientais, permitindo ainda, a identificação dos aspectos a serem modificados no processo de desenvolvimento.

\section{Referências}

BAJAY, S. V. (2001). Relatório Técnico: Reestruturação do MME e criação de um órgão de apoio. Secretaria de Energia, Ministério de Minas e Energia - Departamento Nacional de Política Energética, Brasília, 2001.

CRUZ, W.S.; TOLEDO NETO, E. (2009). A Avaliação ambiental estratégica como instrumento para a solução de conflitos do licenciamento ambiental na regulação do petróleo. In: VI Congresso Brasileiro de Regulação - ABAR, Rio de Janeiro.

EPE-EMPRESA DE PESQUISA ENERGÉTICA (2005). A bio-eletricidade na base do planejamento energético brasileiro, Rio de Janeiro.

EPE-EMPRESA DE PESQUISA ENERGÉTICA (2007). Plano Nacional de Energia 2030, Rio de Janeiro.

HOUGHTON, J.T.; JENKINS, G.J.; EPHRAUMS, J.J. (eds.) (1990). Climate change: The IPCC scientific assessment. Cambridge University Press, Cambridge.

MACHADO JÚNIOR, Z.S.; MACULAN, N.; COSTA, J.P.; et al. (2002). Planejamento da Expansão da Oferta de Energia Elétrica Considerando Incertezas e Garantia de Suprimento. In: VIII Simpósio de Especialistas em Planejamento da Operação e Expansão Elétrica", Brasília, DF, Brasil.

MARIANO, J.B. (2007). Proposta de Metodologia de Avaliação Integrada de Riscos e Impactos Ambientais para Estudos de Avaliação Ambiental Estratégica do setor de petróleo e gás natural em áreas offshore. p.592. Tese (Doutorado em Ciência em Planejamento Energético) - Universidade Federal do Rio de Janeiro, Rio de Janeiro.
MINISTÉRIO DO MEIO AMBIENTE (2002). Avaliação Ambiental Estratégica, Brasília: MMA/SQA, p.92

OBERLING, D.F. (2008). A Avaliação Ambiental Estratégica da Expansão de Etanol no Brasil: uma proposta metodológica e sua aplicação preliminar. p 225. Dissertação (Mestrado em Ciência em Planejamento Energético) - Universidade Federal do Rio de Janeiro - Rio de Janeiro.

OECD-ORGANIZATION FOR ECONOMIC CO-OPERATION AND DEVELOPMENT (1992). The state of the environment. OECD, Paris.

SADLER, B. (org.) (1996). Environmental Assessment in a Changing World: Evaluating practice to improve performance. Canadian Environmental Assessment Agency/International Association for Impact Assessment, p.248.

SÁNCHEZ, L.E. (2008). Avaliação Ambiental Estratégica e sua Aplicação no Brasil. Texto preparado como referência para o debate "Rumos da Avaliação Ambiental Estratégica no Brasil", realizado em 9 de dezembro de 2008 no Instituto de Estudos Avançados da Universidade de São Paulo. Disponível em: < http://www.iea.usp.br/iea/aaeartigo.pdf > Acesso em: 26 jan. 2009.

SANTOS, R.F. (2006). Planejamento ambiental - Teoria e Prática. São Paulo: Ed. Oficina de Textos. São Paulo.

SHEPHERD, A.; ORTOLANO, L. (1996). Strategic Environmental Assessment for Sustainable Urban Development. Georgia Institute of Technology, Atlanta, GA 30332-0155, U.S.A. Elsevier Science Inc 16. 1996. p. 321-335 
TEIXEIRA, I.M.V. (2008). O uso da Avaliação ambiental estratégica no planejamento da oferta de blocos para exploração e produção de petróleo e gás natural no Brasil: uma proposta. p. 302. Tese (Doutorado em ciências em planejamento energético) - Universidade Federal do Rio de Janeiro, Rio de Janeiro.

THERIVEL, R. (2004). Strategic Environmental Assessment in action. London: Earthscan Publications Ltd.
THERIVEL, R.; WILSON, E.; THOMPSON, S.; et al. (1992). Strategic environmental assessment. London: Earthscan Publications Ltd.

ZIMMERMANN, M.P. (2007). Aspectos técnicos e legais associados ao planejamento da expansão de energia elétrica no novo contexto regulatório brasileiro. p 290. Dissertação (Mestrado em engenharia elétrica) - Pontifica Universidade Católica do Rio de Janeiro, Rio de Janeiro. 